\title{
HNF1A-AS1 promotes growth and metastasis of esophageal squamous cell carcinoma by sponging miR-214 to upregulate the expression of SOX-4
}

\author{
GUANNAN WANG, WUGAN ZHAO, XIANZHENG GAO, \\ DANDAN ZHANG, YE LI, YANPING ZHANG and WENCAI LI
}

Department of Pathology, The First Affiliated Hospital, Zhengzhou University, Zhengzhou, Henan 450052, P.R. China

Received March 16, 2017; Accepted May 22, 2017

DOI: $10.3892 /$ ijo.2017.4034

\begin{abstract}
Esophageal squamous cell carcinoma (ESCC) is one of the most common malignancies in the world, marked by dysphagia and weight loss, bringing great suffering to patients. HNF1A-AS1 (HAS1), a long non-coding RNA (lncRNA), has been identified prevalently involved in various human cancers. However, the exact effects and molecular mechanisms of HAS1 in ESCC progression are still elusive. In this study, upregulated expression of HAS1 was detected in ESCC tissues and four human ESCC cell lines (KYSE70, KYSE450, EC109 and EC970) compared with normal tissues and cell lines Small interfering RNA (siRNA)-mediated knockdown of HAS1 largely suppressed cell proliferation and promoted cell apoptosis in KYSE70 and EC109 cells. The decreased expression of proliferation marker proteins and elevated level of apoptosis marker proteins further verified that HAS1-siRNA suppressed cell viability in ESCC cells. Besides, the silence of HAS1 strongly reduced the wound closing rate and the number of invasive cells compared with control group. HAS1siRNA also restrained the expression of migration marker proteins matrix metalloproteinase-9 (MMR-9) and vascular endothelial cell growth factor (VEGF). In addition, miR-214 was predicted as a direct target of HASI by bioinformatics

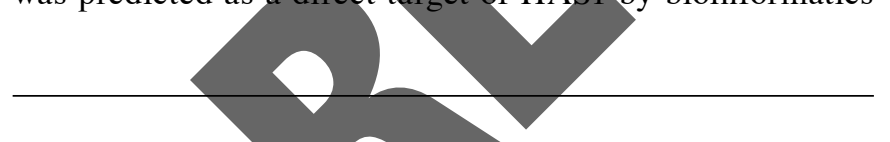

Correspondence to: Dr Wencai Li,Department of Pathology, The First Affiliated Hospital, Zhengzhou University, 1 Jianshe Road, Erqi, Zhengzhou, Henan 450052, P.R. China

E-mail: liwencaihnzz@163.com
\end{abstract}

Abbreviations: ESCC, esophageal squamous cell carcinoma; HAS1, HNF1A-AS1; lncRNA, long non-coding RNA; siRNA, small interfering RNA; MMP, metalloproteinase; VEGF, vascular endothelial cell growth factor; miRNAs, microRNAs; 3'-UTR, 3'-untranslated region; SOX, sex-determining region Y-related high-mobility-group box transcription factor; qRT-PCR, quantitative real-time polymerase chain reaction; CCK-8, cell counting kit-8; PCNA, proliferation cell nuclear antigen

Key words: HNF1A-AS1, microRNA-214, SOX-4, ESCC, growth, metastasis analysis. Downregulated expression of miR-214 was elevated in KYSE70 and EC109 cells transfected with HAS1-siRNA. Subsequently, elevated expression of miR-214 was suppressed by co-transfecting with miR-214 inhibitor in EC109 cells pretreated with HAS1-siRNA. The result of luciferase activity assay showed that luciferase activity was strongly weakened by the combination of LncR-HAS1 WT and miR-214 mimic. Moreover, the expression of SOX-4, a predicted target gene of miR-214, was suppressed by HAS1-siRNA and was increased by miR-214 inhibitor. HAS1-siRNA counteracted the effect of miR-214 inhibitor on cell viability and mobility in EC109 cells. Finally, the in vivo experiment revealed that HAS1-siRNA abated the role of miR-214 inhibitor in promoting tumor growth and metastasis. miR-214 also mediated the effect of HAS1 on upregulating the expression of SOX-4 in vivo. Taken together, our study indicated a HAS1-miR-214-SOX-4 pathway in regulating the growth and metastasis of ESCC, providing a promising target for ESCC therapy.

\section{Introduction}

Esophageal squamous cell carcinoma (ESCC) is one of the most frequent malignancies in human, accounting for $~ 90 \%$ of esophageal cancer worldwide (1). China is a country with high incidence of esophageal cancer, and is one of the countries with the highest mortality rate of esophageal cancer. In recent years, the incidence of ESCC is increasing and the number of male patients is 3-4 times more than female patients due to the use of tobacco and alcohol (2). Actual major treatments for ESCC are surgery combined with neoadjuvant radiation and/or chemotherapy, but the 5-year survival rates is still $<15 \%(3,4)$. Lacking of reliable markers and high aggressiveness are the primary reasons for the poor prognosis and high recurrence rate in ESCC therapy $(5,6)$. So it is urgent to achieve a thorough understanding of the pathogenesis of ESCC.

Long non-coding RNAs (lncRNAs) are RNAs >200 nucleotides but without protein-coding functions $(7,8)$. Substantial studies have revealed the regulating role of lncRNA in cancer development and progression $(9,10)$. HNF1A-AS1 (HAS1) is a bidirectional lncRNA located at chromosome 12q24.31 and is one of three isoenzymes responsible for cellular hyaluronan synthesis (the other two are HAS2 and HAS3) $(11,12)$. Data 
from different groups have reported that HAS1 is involved in metabolic syndrome, inflammation, and cancers. Previous studies have demonstrated the role of HAS1 as a predictor in breast cancer, and the high expression of HAS1 is correlated with high relapse rate and short overall survival (13). Other studies also proved that HAS1 was a poor prognostic biomarker in non-small cell lung cancer and the expression of HAS1 was significantly associated with tumor node metastasis (TNM) stage (14). However, functional involvement of HAS1 in ESCC has not been extensively reported.

MicroRNAs (miRNAs) are a group of non-coding RNAs with 19-24 nucleotides and have been implicated as important regulators in the pathogenesis of human cancers (15). miRNAs regulate biological processes by base pairing with the 3'-untranslated region (3'-UTR) of target mRNA sequences (16). Aberrant expression of miRNAs in cancer cell lines and tissues is closely related to tumor growth, invasion and metastasis $(17,18)$. Previous research revealed that miR-214 is a molecular hub involved in the control of cancer networks and could be a potential diagnostic/prognostic biomarker and target for therapeutic intervention (19). Here we set to explore the regulating role of miR-214 in the pathogenesis of ESCC.

Sex-determining region Y-related high-mobility-group box transcription factor genes (SOX) are involved in the transcription processes during embryonic development and organogenesis $(20,21)$. Previous studies suggested that SOX4 was upregulated in various cancers and SOX4 might function as an oncogene or a tumor suppressor in different typ of cancers. For example, increased expression of SOX4 was found in colorectal cancer tissues and the inhibition of SOX suppressed CRC cell proliferation, and invasion (22). SOX4 also acted as a suppressor in the growth of glioblastoma, partly by activating p53-p21 signaling to induce G0/G1 cell cycle arrest (23). Moreover, SOX4 was found upregulated in ESCC and the SOX-Wnt interaction was identified to be involved in the development of ESCC (24). The specific regulatory mechanism remains to be further explored.

In this study, we aimed to explore the mechanism of HAS1 in the growth and metastasis of ESCC. Upregulated HAS1 was found in ESCC tissues and celllines. Small interfering RNA (siRNA)-mediated knockdown of HAS1 restrained cell proliferation and induced cell apoptosis in ESCC cells. HAS1-siRNA also suppressed the mobility of ESCC in vitro and in vivo and may be sponging miR-214 to upregulate the expression of SOX-4. The HAS1-miR-214-SOX-4 pathway may be useful in the development of ESCC treatment.

\section{Materials and methods}

Sample collection. Thirty-five pairs of human ESCC tissues and adjacent normal tissues were obtained from The First Affiliated Hospital of Zhengzhou University. The tissues were stored at $-80^{\circ} \mathrm{C}$ until needed. The study was performed in accordance with the Helsinki Declaration and was approved by the Human Ethics Committee/Institutional Review Board of The First Affiliated Hospital of Zhengzhou University.

Cell lines. The human ESCC cell lines KYSE70, KYSE450, EC109, EC970 and esophageal epithelial cell line HET-1A were purchased from American Type Culture Collection (Manassas, VA, USA). All the cell lines were maintained routinely in RPMI-1640 media (Gibco, cat. no. 11875-093) supplemented with $10 \%$ fetal bovine serum (Life Technologies, Inc., Grand Island, NY, USA) and grown at $37^{\circ} \mathrm{C}$ in humidified air containing $5 \% \mathrm{CO}_{2}$.

Quantitative real-time polymerase chain reaction ( $q R T-P C R$ ). qRT-PCR was performed to assess the expression level of miRNA. Total RNA from the tissue samples or cultured cells was extracted using the TRIzol reagent (Invitrogen, Carlsbad, CA, USA) according to the manufacturer's instructions. qRT-PCR was performed by using SYBR-green PCR Master Mix in a Fast Real-time PCR 7500 system (Applied Biosystems). The RT-PCR primers for HAS1 and miR-214 were purchased from GeneCopoeia (San Diego, CA, USA). The specific primers were as follows: HAS1 forward, 5'-TCA AGAAATGGTGGCTAT-3'; reverse, 5'-GCTCTGAGACTG GCTGAA-3'. miR-214 forward, 5'-AGCATAATACAGCA GGCACAGAC-3; reverse, 5-AAAGGTTGTTCTCCACTCT CTCAC-3'. GAPDH was used as the internal control of the mRNA or miRNA, respectively Fold change of HAS1 or miR-214 was calculated by the equation $2^{-\Delta \Delta \mathrm{Ct}}$.

thern blotting. The expression levels of HAS1 and miR-214 in ESCC samples, adjacent normal tissues, ESCC cell lines (KYSE70, KYSE450, EC109 and EC970), and esophageal epithelial cell line HET-1A were further determined by northern blot assay. Northern blot analysis was performed as previously described (25).

Lentiviral vector construction and cell transfection. Mimics/ inhibitors specific for miR-214 and siRNA/scramble fragments targeting HAS1 were designed and purchased from Invitrogen. KYSE70 and EC109 cells were seeded in 24-well plates ( $1 \times 10^{5}$ cells per well). HAS1 siRNA and scramble fragments were amplified using Primer STAR premix (Takara) and cloned into lentivirus vector according to the manufacturer's protocol, respectively. KYSE70 and EC109 cells were transfected with recombinant lentivirus. Mimics/inhibitors specific for miR-214 were transfected into KYSE70 and EC109 cells using Lipofectamine 3000 (Invitrogen) according to the manufacturer's protocol. Cells were harvested $48 \mathrm{~h}$ after transfection for subsequent experiments.

Cell proliferation assay. Cell proliferation was assayed using the cell counting kit-8 (CCK-8, Dojindo Laboratories, Tokyo, Japan) according to the manufacturer's protocol. A total of $\sim 5 \times 10^{3}$ cells were seeded onto 96-well plates. KYSE70 and EC109 cells were pretreated with HAS1-siRNA or siRNA-scramble, respectively. Then cells were incubated with CCK- 8 solution for another $2 \mathrm{~h}$ at $37^{\circ} \mathrm{C}$. The absorbance was measured at $450 \mathrm{~nm}$ using multifunctional microplate reader spectraMax M5 (Molecular Devises, CA, USA) at indicated time-points. All experiments were repeated at least three times.

Flow cytometric analysis of cell apoptosis. Cells in each group were harvested at $48 \mathrm{~h}$ post-transfection. For the apoptosis analysis, cells were collected, washed twice with 
cold PBS, resuspended and fixed, then were stained using the Annexin V-fluorescein isothiocyanate (FITC) and PI apoptosis detection kits (Annexin V-FITC Apoptosis Detection kit, eBioscience). The cells were examined by the FACSCaliber II sorter and Cell Quest FACS system (BD Biosciences, San Jose, CA, USA) according to the manufacturer's protocols. The flow cytometry analysis was repeated at least three times.

Western blot analysis. The proteins extracted from tissues and cultured cells were separated through SDS-PAGE and then transferred onto polyvinylidene fluoride (PVDF) membranes (Millipore, Billerica, MA, USA). The membranes were blocked in PBST (PBS with $0.1 \%$ Tween-20) containing $5 \%$ non-fat milk for $2 \mathrm{~h}$ at room temperature, and then were incubated with the primary antibodies: anti-Ki67, antiproliferation cell nuclear antigen (PCNA), anti-caspase-3, anti-caspase-9, anti-metalloproteinase (MMP)-9, antivascular endothelial cell growth factor (VEGF), anti-SOX-4, anti-GAPDH and corresponding HRP-conjugated secondary antibodies. Membranes were extensively washed several times with PBST. Proteins were detected using a ChemiDoc XRS imaging system and Quantity One analysis software (Bio-Rad, San Francisco, CA, USA). GAPDH (Abcam) was used as an endogenous reference.

Wound healing assay. Wound-healing assay was performed to evaluate the migration rate of KYSE70 and EC109 cells transfected with HAS1-siRNA or siRNA-scramble or control. Approximately $1.5 \times 10^{6}$ cells/well were seeded in 6-well plate and cultured overnight until the cells reached $90 \%$ confluence. Then a straight scratch was created by a sterile pipette tip. After rinsing off the destroyed cells with PBS, the plate was cultured in medium for another $24 \mathrm{~h}$ observed and imaged at 0 and $24 h$ (Leica DFC300FX).

Transwell invasion assay. For the invasion assays, KYSE70 and EC109 cells pre-treated withHAS1-siRNA or siRNA scramble $\left(2 \times 10^{4}\right.$ cells/well) were placed in Transwell cell culture chambers (8-mm pore size; Merck Millipore Corp.) and were coated with Matrigel (Becton-Dickinson, NJ, USA). Cell suspension was placed in the upper chamber of the insert and the lower chamber was filled with medium containing $10 \% \mathrm{FBS}$. After incubation for another $24 \mathrm{~h}$, the invasive cells that had transferred to the lower chamber were fixed in 95\% ethanol, stained with hematoxylin and were quantified under a light microscope at $100 \mathrm{X}$ in five random fields per membrane. Each sample was assayed in triplicate.

Luciferase activity assay. The Luc-HAS1-WT and LucHAS1-MUT were constructed as follows. The wild-type 3'-UTR and mutant 3'-UTR (modified miR-214 binding site) HAS1 RNA were amplified by chemical synthesis and were inserted into a luciferase reporter vector (pGL4.74) to generate Lnc-HAS1 WT and Lnc-HAS1-MUT constructs, respectively. EC109 cells were co-transfected with $0.1 \mu \mathrm{g}$ Lnc-HAS1 WT/ Lnc-HAS1-MUT and/or $40 \mathrm{nM}$ miR-214 mimic for $24 \mathrm{~h}$. Similarly, the wild-type 3'-UTR and mutant 3'-UTR (modified miR-214 binding site) SOX-4 RNA were amplified by chemical synthesis and were inserted into a luciferase reporter vector (pGL4.74) to generate SOX-4 WT and SOX-4 MUT constructs, respectively. EC109 cells were co-transfected with $0.1 \mu \mathrm{g}$ SOX-4 WT/SOX-4 MUT and/or $40 \mathrm{nM} \mathrm{miR-214} \mathrm{mimic}$ for $24 \mathrm{~h}$. Luciferase activities were detected by a dual-luciferase reporter system according to the manufacturer (Promega, E2920). The experiments were performed in triplicate.

Subcutaneous xenograft mouse model. All animal experiments were carried out in accordance with a protocol approved by the Institutional Animal Care and Use Committee (IACUC). The xenografted mouse model was conducted as previously described $(26,27)$. EC109 cells were transfected with HAS1-siRNA and/or miR-214 inhibitor or siRNAscramble for $24 \mathrm{~h}$. Then, $4 \times 10^{6}$ cells were subcutaneously inoculated into 6-8 weeks old male athymic nude mice. After tumors $\left(100-150 \mathrm{~mm}^{3}\right)$ had established, the tumor volume was measured every 5 days using the same protocol, and calculated in length $\mathrm{x}\left(\right.$ width $\left.^{2}\right) / 2$.

Immunohistochemistry. Formalin-fixed paraffin-embedded sections $(5 \mu \mathrm{M})$ from tissue microarrays were prepared. They were deparaffinized in xylene and rehydrated then were incubated in $30 \% \mathrm{H}_{2} \mathrm{O}_{2}$ to quench the activity of endogenous peroxidase. Then the sections were incubated with primary antibodies directed against VEGF overnight at $4^{\circ} \mathrm{C}$. Proteins were visualized undera light microscope.

Statistical analysis. All results are presented as mean \pm SD and evaluated with a Student's t-test. All experiments were performed at least three times and performed in triplicate. Statistical significance was considered at $\mathrm{P}$-value $<0.05$.

\section{Results}

The level of HASl is elevated in ESCC. In order to investigate the role of HAS1 in ESCC, relative expression of HAS1 in ESCC tissues and cell lines was detected by qRT-PCR and western blotting. As shown in Fig. 1A, relative expression of HAS1 in ESCC tissues was $\sim 3$ times more than the normal tissue $\left({ }^{* *} \mathrm{P}<0.01\right)$. Western blot analysis was in line with the q-PCR result and further confirmed that the level of HAS1 was upregulated in ESCC tissues compared with normal tissues (Fig. 1B). Then, the expression of HAS1 in esophageal epithelial cell line (HET-1A) and a panel of ESCC cell lines including KYSE70, KYSE450, EC109 and EC970 was further measured. Compared with HET-1A group, the expression of HAS1 was strongly increased in ESCC cell lines $\left({ }^{* *} \mathrm{P}<0.01\right.$, Fig. 1C and D). The elevated expression of HAS1 in ESCC tissues and cell lines suggested that HAS1 was involved in the pathogenesis of ESCC.

Inhibition of HAS1 reduces cell viability. We then tested the functional significance of HAS1 in ESCC cells lines. KYSE70 and EC109 cell lines were transfected with HAS1-siRNA or siRNA scramble, respectively. The expression of HAS1 was successfully reduced by HAS1-siRNA as shown in Fig. 2A and $2 \mathrm{~B}\left({ }^{* *} \mathrm{P}<0.01\right)$. Then, the result of CCK8 assay showed that the inhibition of HAS1 largely suppressed cell proliferation in KYSE70 and EC109 cells ( ${ }^{* *} \mathrm{P}<0.01$, Fig. 2C). Additionally, the effect of HAS1 on cell apoptosis was valued through flow 

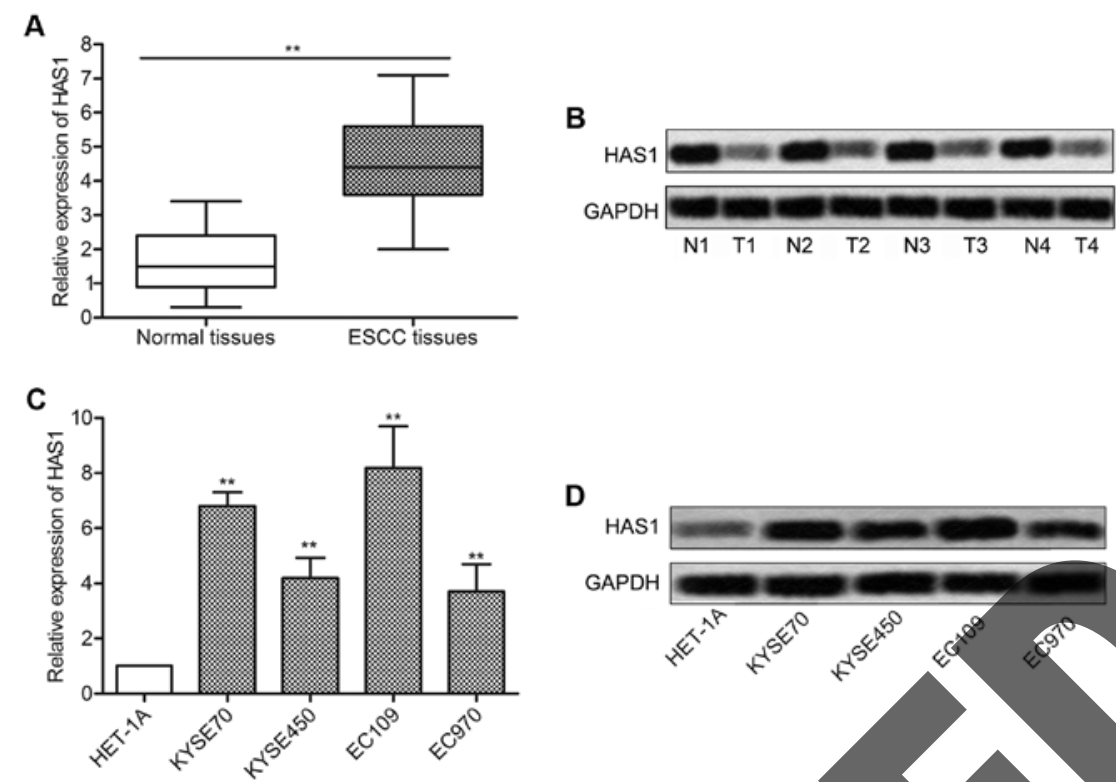

D

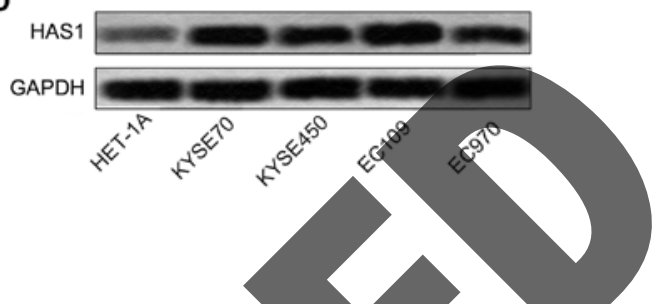

Figure 1. The level of HAS1 is elevated in ESCC. (A) Relative expression of HAS1 in ESCC tissues and adjacent histologically normal tissues was detected by qPCR $\left({ }^{* *} \mathrm{P}<0.01\right.$ versus normal tissues). (B) Expression of HAS1 in ESCC tissues and adjacent histologically normal tissues was detected through northern blotting. GAPDH was used as an endogenous reference. (C) The expression of HAS1 in ESCC cell lines (KYSE70, KYSE450, EC109 and EC9706) and esophageal epithelial cell line (HET-1A) was detected through qRT-PCR ( $(P<0.01$ versus HET-1A). The bars show means \pm SD of three independent experiments. (D) Expression of HAS1 in related ESCC cell lines and esophageal epithelial cell line was evaluated through northern blotting. GAPDH was used as an endogenous reference. The bars show means \pm SD of three independent experiments.
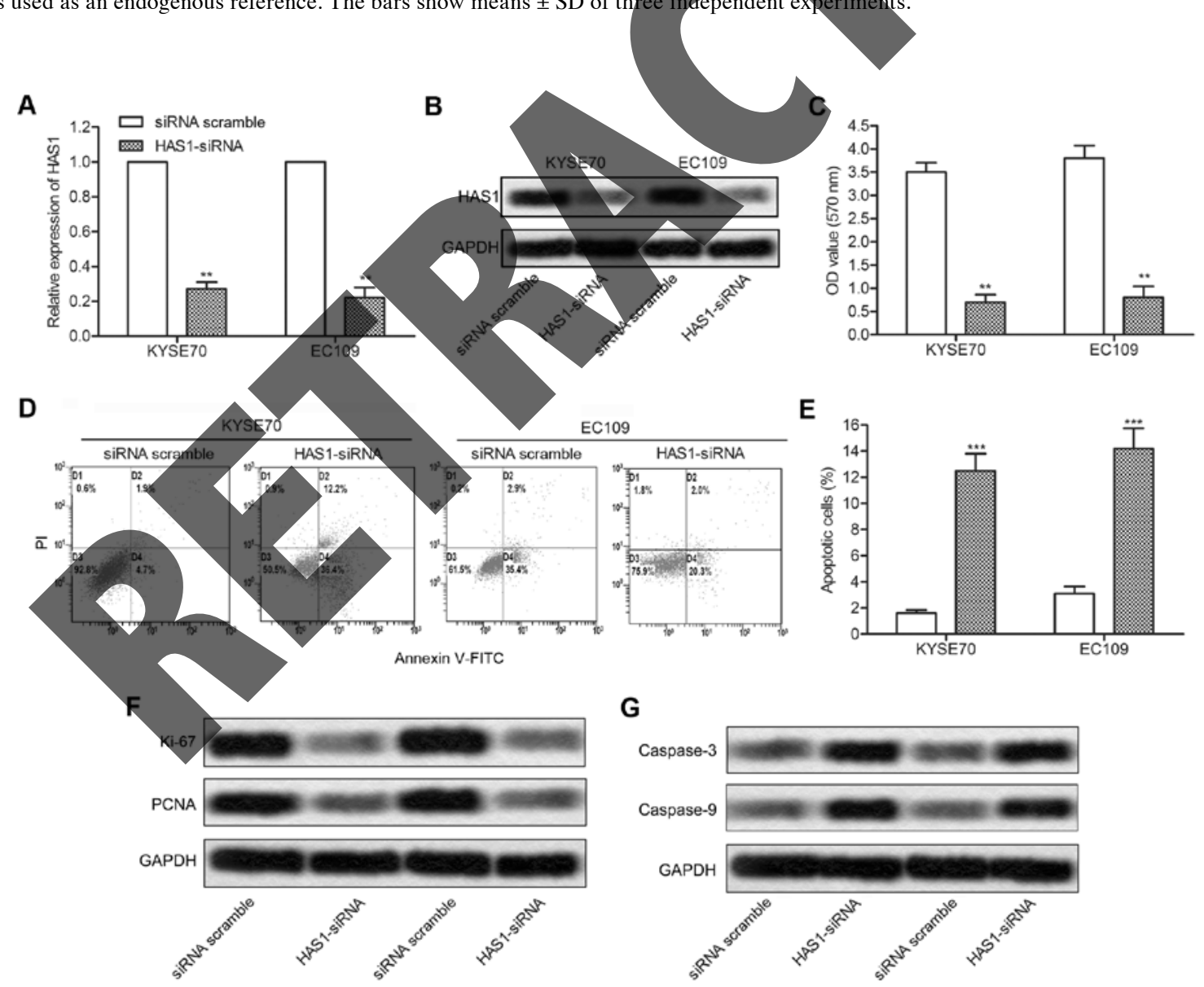

Figure 2. Inhibition of HAS1 reduces cell viability. KYSE70 and EC109 cell lines were transfected with HAS1-siRNA or siRNA scramble, respectively. (A) Relative expression of HAS1 in KYSE70 and EC109 cells was detected through qRT-PCR ( ${ }^{* *} \mathrm{P}<0.01$ versus scramble group). (B) Expression of HAS1 in KYSE70 and EC109 cells was detected through northern blotting. GAPDH was used as an endogenous reference. (C) The numbers of cells per well in KYSE70 and EC109 cells were measured through CCK8 assay at $570 \mathrm{~nm}$. The statistical results are shown in the histogram $\left({ }^{* *} \mathrm{P}<0.01\right.$ versus scramble group). (D) Cell apoptosis was detected using flow cytometry. (E) Histogram presents the statistical analysis of cell apoptosis rate $\left({ }^{* * *} \mathrm{P}<0.01\right.$ versus scramble group). (F) The expression of cell proliferation markers (Ki67 and PCNA) was detected through western blotting. (G) The expression of cell apoptosis markers (caspase- 3 and caspase-9) was detected through western blotting. GAPDH was used as an endogenous reference. The bars show means \pm SD of three independent experiments. 
A

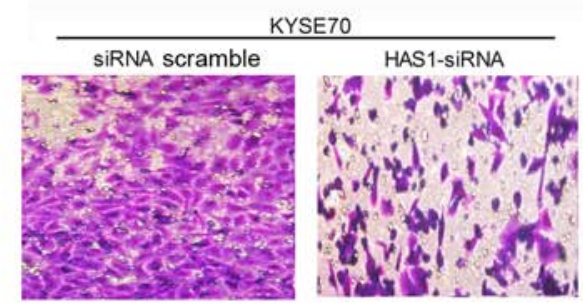

C
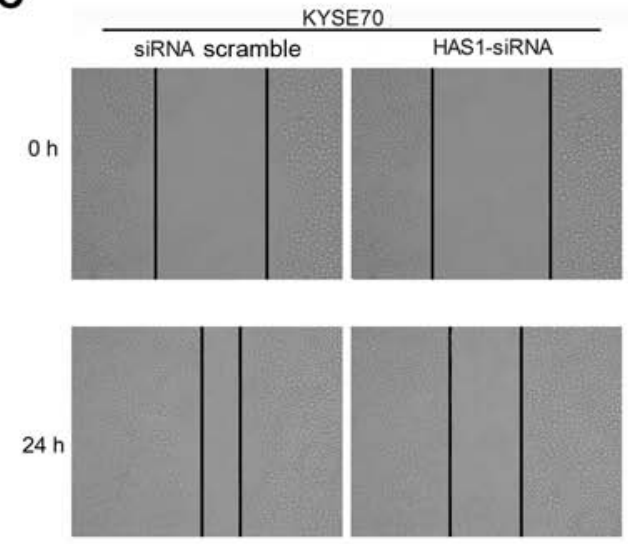

E
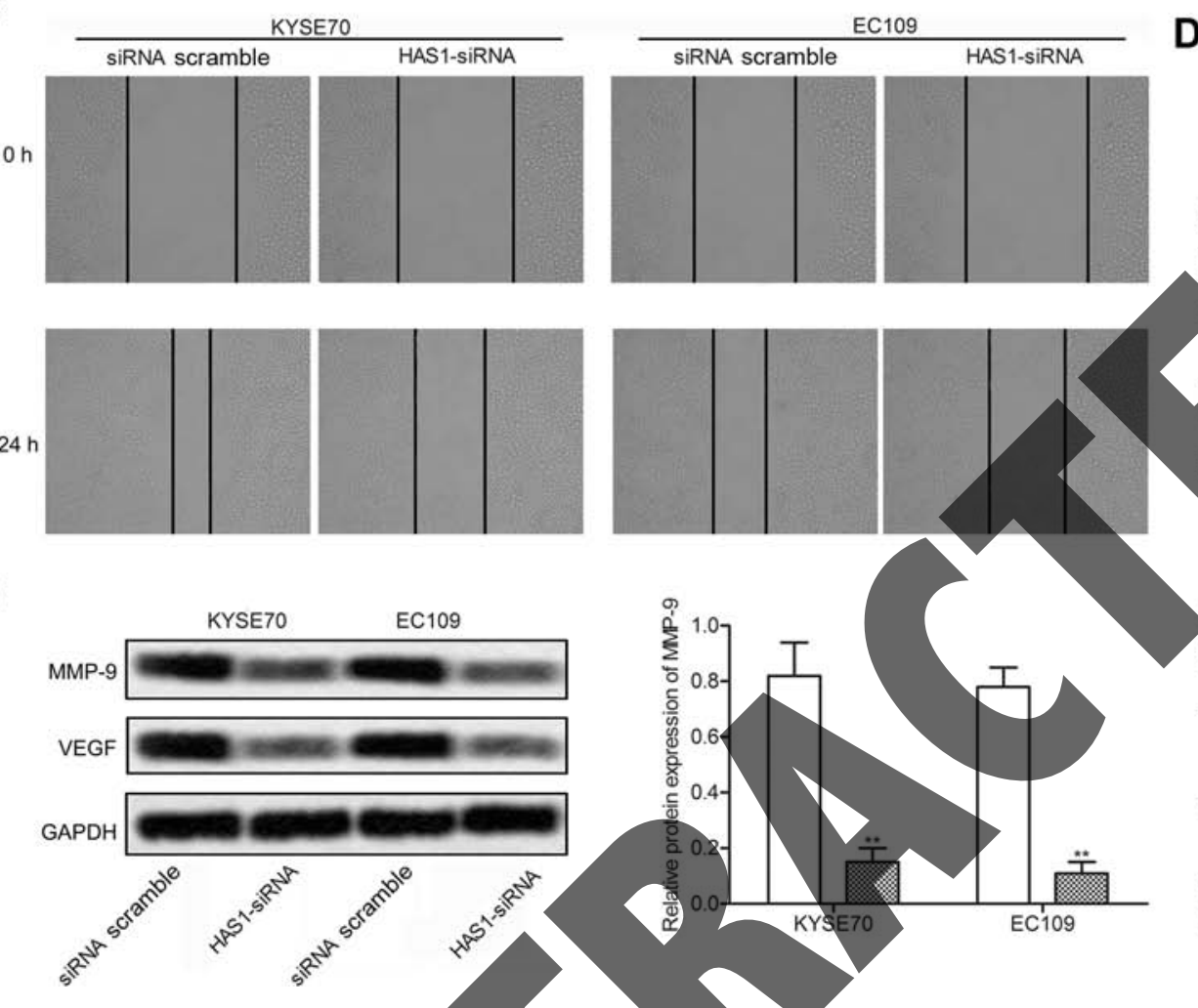

D
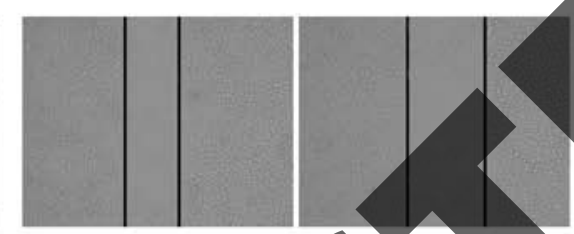

B
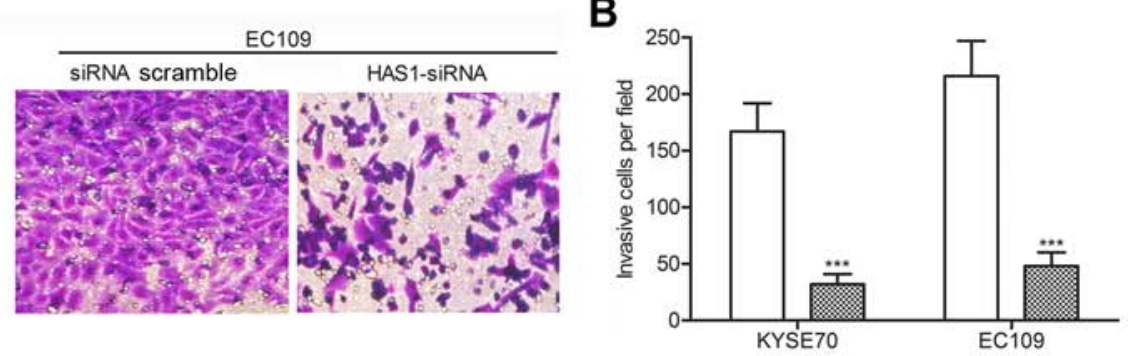

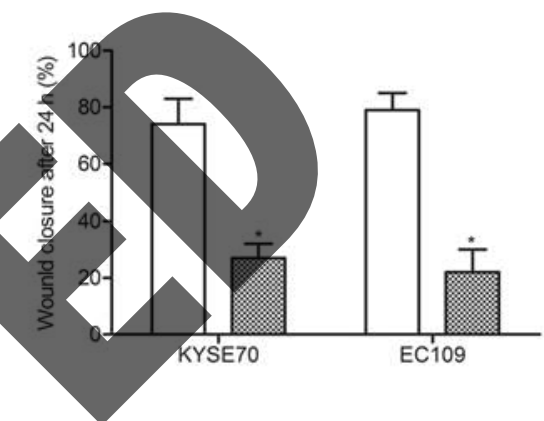
Figure 3. Inhibition of HAS1 suppresses cell motility. KYSE70 and EC109 cell lines were transfected with HAS1-siRNA or siRNA scramble, respectively.
(A) Transwell invasion assay was conducted to observe the invasive cells in KYSE70 and EC109 cells. (B) Histogram represents the statistical analysis of Transwell invasion assay ( ${ }^{* * *} \mathrm{P}<0.001$ versus scramble group). (C) The migration rate of KYSE70 and EC109 cells was observed through wound-healing assays. (D) Histogram presents the statistical analysis of wound-healing assays $\left({ }^{* *} \mathrm{P}<0.01\right)$. (E) The expression of migration marker proteins MMP-9 and VEGF in KYSE70 and EC109 cells were evaluated by western blotting and qRT-PCR ( ${ }^{*} \mathrm{P}<0.01$ versus scramble group). GAPDH was used as an endogenous reference. The bars show means \pm SD of three independent experiments.

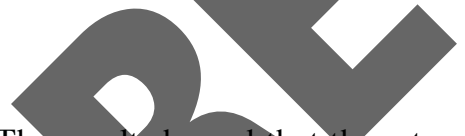

cytometry. The result showed that the rate of apoptotic cells was markedly increased in HASI-siRNA group compared with the scramble group ${ }^{* * *} \mathrm{P}<0.001$, Fig. $2 \mathrm{D}$ and $\left.\mathrm{E}\right)$. The expression of cell proliferation and apoptosis related proteins was then detected through western blotting. Decreased expression of proliferation markers Ki67 and PCNA and increased level of apoptosis markers (caspase-3 and caspase-9) further revealed that HAS1-siRNA suppressed cell proliferation and induced cell apoptosis in ESCC cells (Fig. 2F and G). Taken together, the results above strongly suggested that inhibition of HAS1 reduced cell viability in ESCC cells.

Inhibition of HAS1 suppresses cell motility. Given that the inhibition of HAS1 reduced cell viability in ESCC cells, further experiments were conducted to examine the effect of HAS1 on cell motility. The result of Transwell invasion assay showed that the number of invaded cells was noticeably declined in KYSE70 and EC109 cells transfected with
HAS1-siRNA $\left({ }^{* * *} \mathrm{P}<0.001\right.$, Fig. $3 \mathrm{~A}$ and B $)$. By comparing the closure of the gap at 0 and $24 \mathrm{~h}$ later after transfection, a significantly decreased closing rate of scratch wounds was detected in HAS1-siRNA group compared with the siRNA scramble group ( ${ }^{*} \mathrm{P}<0.05$, Fig. $3 \mathrm{C}$ and $\left.\mathrm{D}\right)$. The expression of migration marker proteins MMP-9 and VEGF was obviously decreased in KYSE70 and EC109 cells transfected with HAS1-siRNA compared with the scramble group $\left({ }^{* *} \mathrm{P}<0.01\right.$, Fig. 3E). The results above indicated that inhibition of HAS1 suppressed cell motility in ESCC.

miR-214 is a direct target of HAS1. Predicted by bioinformatics analysis, three complementary sites of miR-214 was found in the sequence of HAS1 RNA (Fig. 4A). Besides, in previous research, miR-214 was found downregulated in ESCC and acted as a diagnostic marker and therapeutic target in ESCC (28). A series of experiments were then conducted to explore the relationship between miR-214 and HAS1 in ESCC. 
A

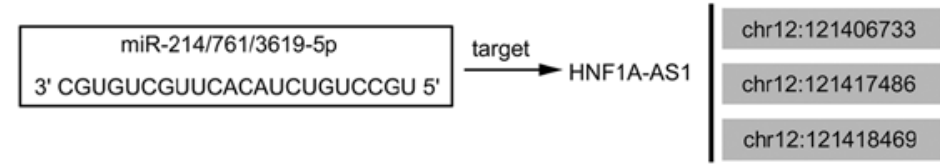

B

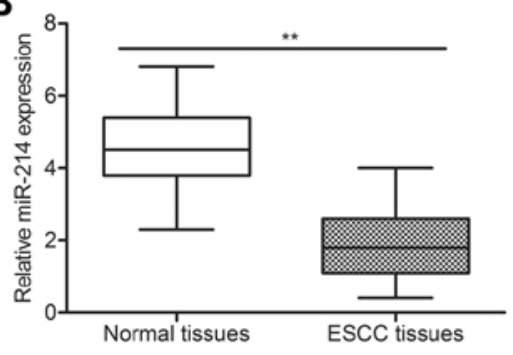

C

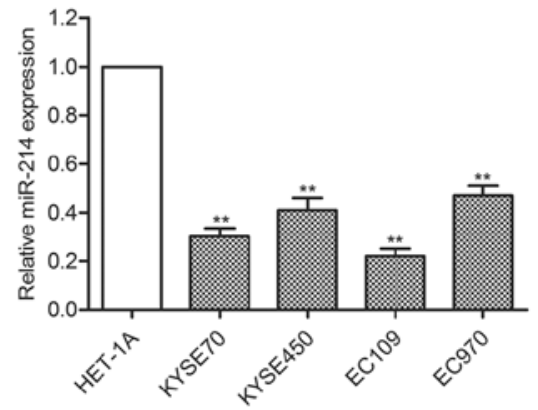

D

G

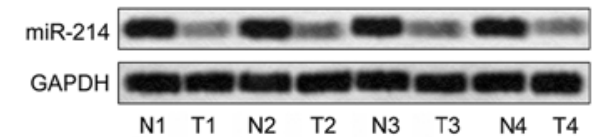

E
$\mathbf{F}$

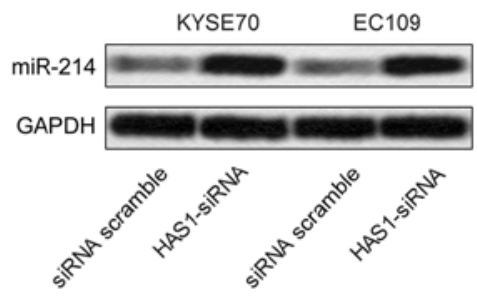

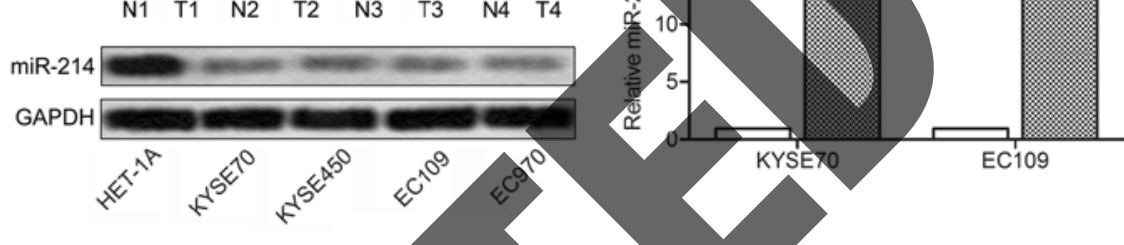

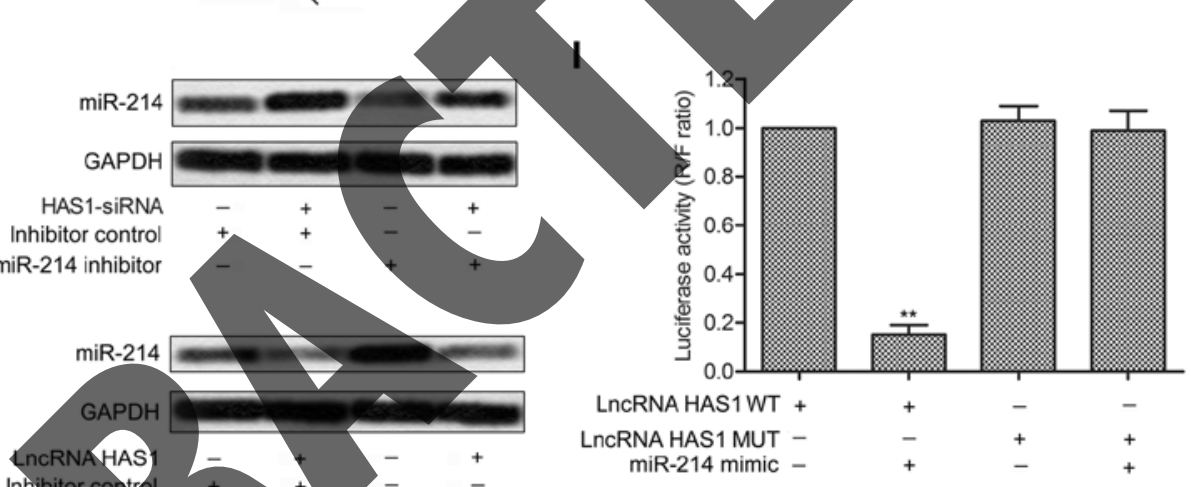

Figure 4. miR-214 is a direct target of HAS1. (A) Complementary sites of miR-214 in HAS1RNA were predicted through bioinformatics analysis. (B) Relative expression of miRNA-214 in ESCC tissues and adjacent histologically normal tissues was detected by qPCR ( ${ }^{* *}<0.01$ versus normal tissues). (C) Relative expression of miRNA-214 in ESCC cell lines (KYSE70, KYSE450, EC109 and EC9706) and esophageal epithelial cell line (HET-1A) was valued through qRT-PCR ( ${ }^{* *} \mathrm{P}<0.01$ versus HET-A). (D) Expression of miR-214 in related tissues and cell lines was measured through northern blotting. GAPDH was used as an endogenous reference. (E and F) KYSE70 and EC109 cell lines were transfected with HAS1-siRNA or siRNA scramble, respectively. Relative expression of miR-214 in KYSE70 and EC109 cells was detected through qRT-PCR and northern blotting (*P<0.05 versus scramble group). (G) EC109 cells were transfected with HAS1-siRNA and/or miR-214 inhibitor or inhibitor control. Expression of miR-214 was detected through northern blotting. (H) EC109 cells were transfected with LncRNA HAS1 and/or miR-214 mimic or mimic control. Expression of miR-214 was detected through northern blotting. (I) Wild-type (LncR-HAS1-WT) or mutant (LncR-HAS1-Mut) luciferase reporter and/or miR-214 mimic were co-transfected into EC109 cells. Luciferase reporter assay was conducted to detect the luciferase activity in EC109 cells ("P<0.05 versus LncR-HAS1-WT group). GAPDH was used as an endogenous reference. The bars showed means \pm SD of three independent experiments.

The expression of miRNA-214 was significantly decreased in ESCC tissues and cell lines (KYSE70, KYSE450, EC109 and EC9706) compared with normal tissues and esophageal epithelial cell line (HET-1A) $\left({ }^{* *} \mathrm{P}<0.01\right.$, Fig. 4B and C). Similar conclusion was further verified through northern blot analysis (Fig. 4D). Interestingly, the expression of miR-214 was strongly increased in KYSE70 and EC109 cells transfected with HAS1-siRNA ( ${ }^{*} \mathrm{P}<0.05$, Fig. $4 \mathrm{E}$ and F). Then, elevated expression of miR-214 was suppressed by miR-214 inhibitor in EC109 cells transfected with LncRNA HAS1 (Fig. 4G). Similarly, decreased expression of miR-214 was upregulated by adding miR-214 mimic in EC109 cells transfected with HAS1-siRNA (Fig. 4H). Luciferase reporter assays showed that relative luciferase activity in LncRNA HAS1 wild-type group was significantly decreased by co-transfecting miR-214 mimic compared with control group $\left({ }^{* *} \mathrm{P}<0.01\right.$, Fig. 4I). All the results above illustrated the fact that miR-214 was a target of HAS1.

The expression of SOX-4 is upregulated by HAS1. According to previous reports, HAS1 and SOX-4 were both involved in the pathogenesis of ESCC, so it is worth exploring the relationship between the two. KYSE70 and EC109 cells were transfected with HAS1-siRNA and/or miR-214 inhibitor or inhibitor control, respectively. The targeting relationship between miR-214 and SOX4 was first predicted through bioinformatics analysis. Luciferase reporter assays further showed that relative luciferase activity in SOX-4 WT group was significantly decreased 
A

hsa-miR-214-5p

SOX4 3' UTR

Position 2391-2398

3' CGUGUCGUUCACAUCUGUCCGU 5'

5' ...UGUUUAAUAUAACAUGACAGGCA...

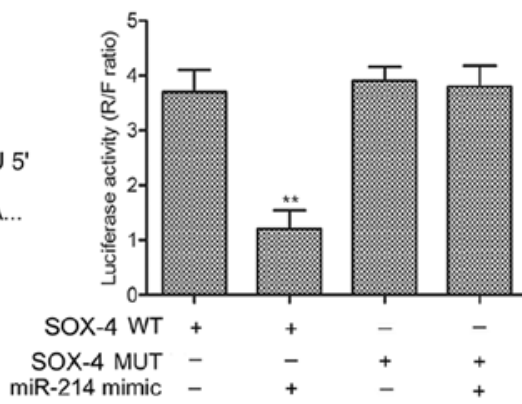

B

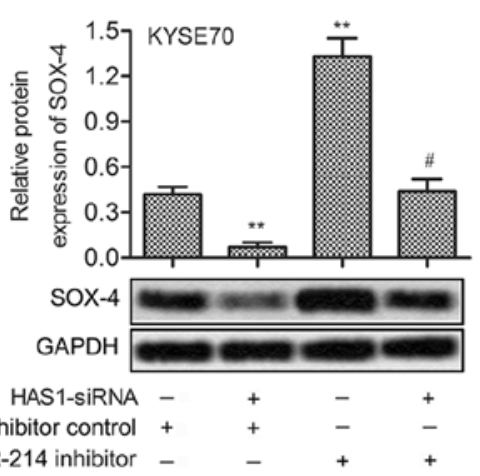

C

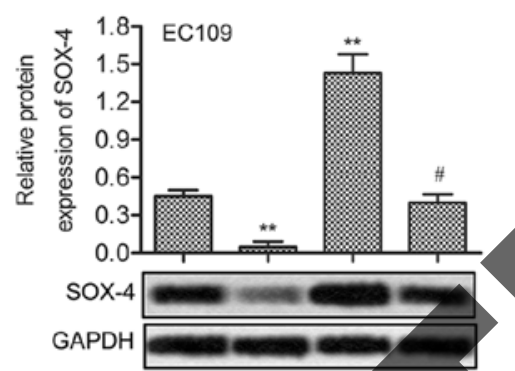

D
E
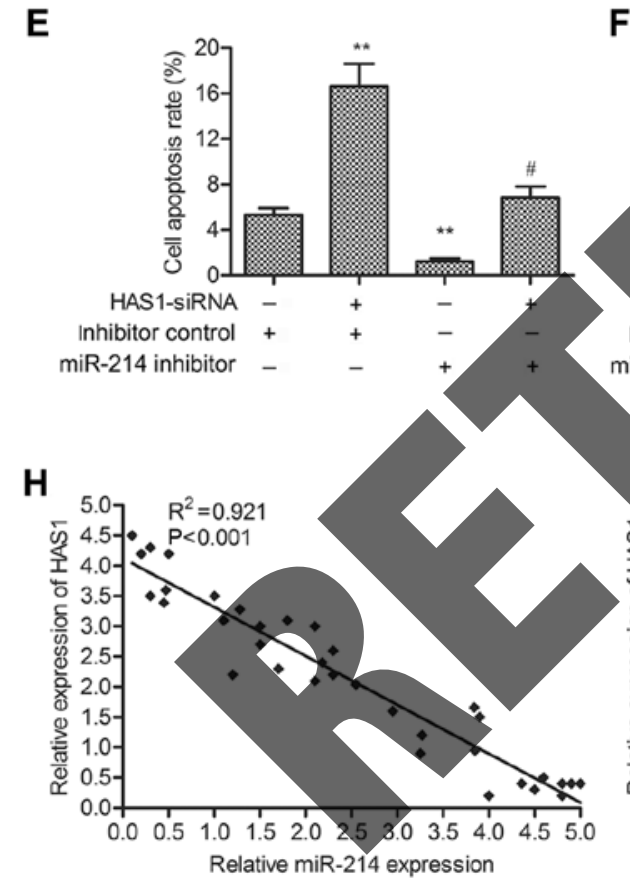

$\mathbf{F}$

HAS1-siRNA Inhibitor control + miR-214 inhibitor -

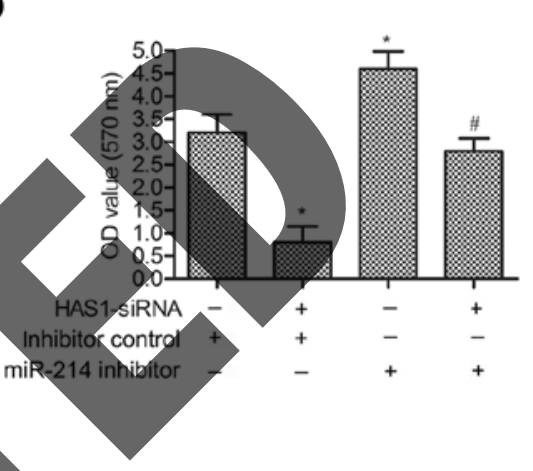


A

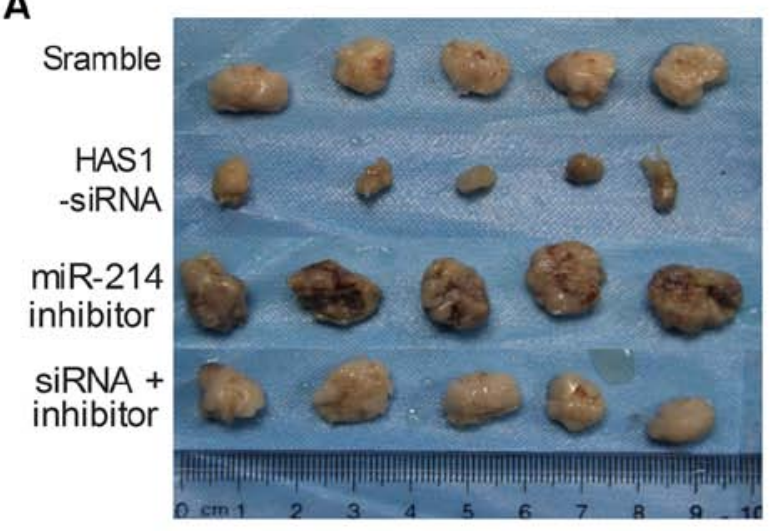

B

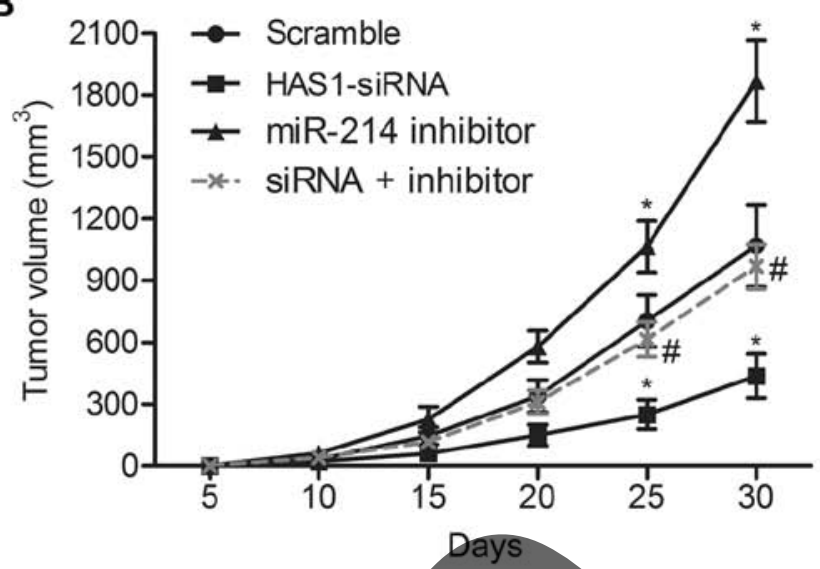

C

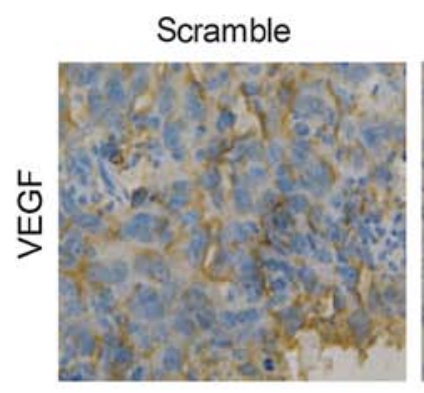

D

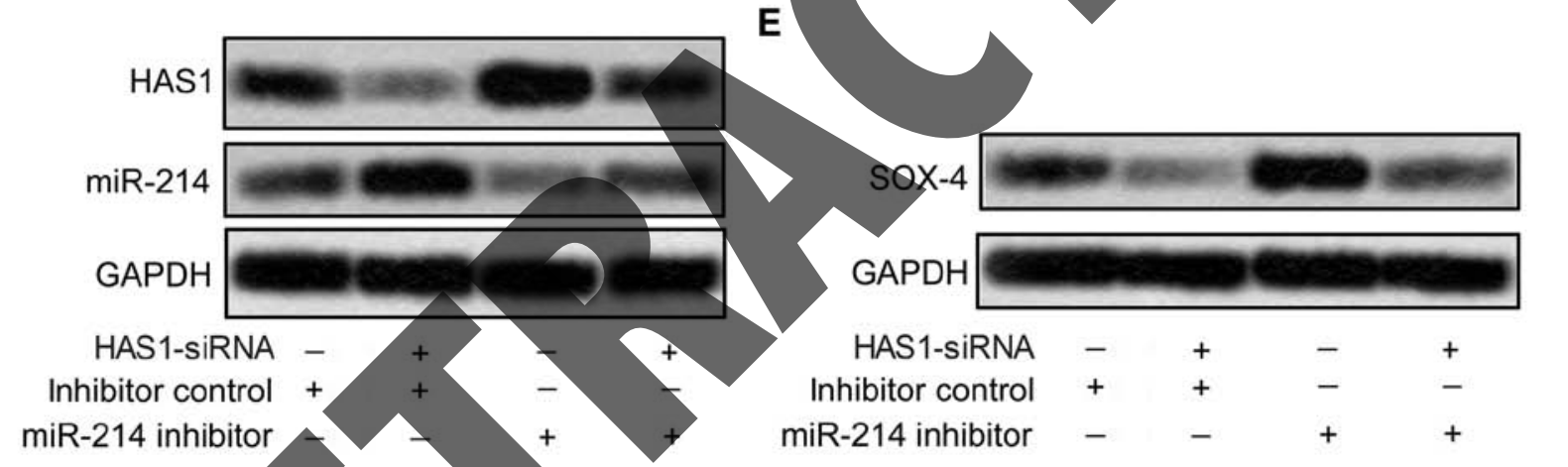

Figure 6. HAS1-siRNA inhibits tumor growth and metastasis in vivo. EC109 cells were pre-treated with HAS1-siRNA or scramble, respectively. ESCC xenograft mouse model was created by subcutaneous injection of recombinant cell lines to SPF nude mice. (A) Representative images of ESCC xenograft tissues are presented $(n=5)$. (B) The diameter of ESCC xenografts in each group was measured every 5 days from tumor formation to 30 days. Tumor growth curve is shown as means \pm SD ( $\mathrm{P}<0.05$ versus scramble group). (C) Expression of migration marker protein VEGF in formalin-fixed, paraffin-embedded tumors from each group of mice was detected through $\mathrm{HHC}$ analysis. (D) Expression of HAS1 and miR-214 in ESCC xenograft tissues was detected through northern blotting. (E) Expression of SOX 4 in ESCC xenograft tissues was detected through western blotting. GAPDH was used as an endogenous reference. The bars show means \pm SD of three independent experiments.

SOX-4 -was decreased by co-transfecting HAS1-siRNA into miR-214 inhibitor-treated cells $\left({ }^{* *} \mathrm{P}<0.01\right.$, Fig. 5B and $\left.\mathrm{C}\right)$. Then, cell viability and motility were valued in EC109 cells treated as described above. miR-214 effectively weakened the effect of HAS1-siRNA inhibiting cell proliferation and promoting cell apoptosis $\left({ }^{*} \mathrm{P}<0.05,{ }^{* *} \mathrm{P}<0.01\right.$, Fig. 5D and E). Similarly, declining number of invasion cells, and cell migration rate was elevated by miR-214 inhibitor in EC109 cells pretreated with HAS1-siRNA ( ${ }^{*} \mathrm{P}<0.05,{ }^{* *} \mathrm{P}<0.01$, Fig. 5F and G). Moreover, relative expression HAS1, miR-214 and SOX4 in 35 paired cases of ESCC tissues were detected by qRT-PCR. The correlational analyses among the three showed a positive relationship between the expression level of HAS1 and SOX4, and a negative relationship between HAS1 and miR-214, miR-214 and SOX4 (Fig. 5H).
HAS1-siRNA inhibits tumor growth and metastasis in vivo. To investigate the effects of HAS1 on migration and invasion of ESCC in vivo, EC109 cells were pre-treated with HAS1-siRNA and/or miR-214 inhibitor or scramble. ESCC xenograft mouse model was created by subcutaneous injection of recombinant cell lines to SPF nude mice. Compared with the scramble group, average tumor volume was obviously smaller in the HAS1-siRNA group ( ${ }^{*} \mathrm{P}<0.05$, Fig. 6A and B). Besides, the expression level of migration marker protein VEGF was also strongly suppressed by HAS1-siRNA compared with the scramble group (Fig. 6C). Moreover, the expression of miR-214 was increased and the expression of SOX4 was suppressed by HAS1-siRNA in EC109 cells (Fig. 6D and E). The results above indicated that HAS1-siRNA inhibited tumor growth and metastasis in vivo. 


\section{Discussion}

ESCC is an aggressive malignancy with poor prognosis and the incidence of ESCC is increasing. The invasion and metastasis characteristics of ESCC cells resulted the high morbidity and mortality of ESCC $(29,30)$. ESCC patients lose the chance of getting a diagnosis in the early stages of the disease due to lack of sufficiently sensitive and specific biomarkers (31). Thus, a better understanding of the mechanisms underlying the growth and metastasis of ESCC is necessary for cancer therapy. In this study, we focused on the role of HAS1 in regulating the growth and invasion of ESCC and the related relevant mechanism.

Accumulated studies have shown the regulating role of lncRNAs in cell proliferation, metastasis, invasion and apoptosis $(32,33)$. HAS1 has been regarded as a promising diagnostic biomarker or therapeutic target for various human cancers. For example, elevated expression of HAS1 in bladder tumor tissues contributed to a positive HA urine test and may have some prognostic potential (34). Upregulated expression of HAS1 was also found in colon cancer (35), ovarian cancer (36) and endometrioid endometrial carcinoma (37), indicating a poor prognosis. However, some other studies demonstrated that decreased expression of HAS1 and HAS2 were associated with poor prognosis in cutaneous melanoma (38). The studies above prove that the aberrant expression of HAS1 is associated with cancer development. In this study, a signifieant upregulated expression of HAS1 was detected in ESCC compared with adjacent histologically normal tissues, and in the corresponding cell lines. These results suggest that HASI is upregulated in ESCC and indicates the possible correlation between HAS1 and ESCC.

The regulating role of HAS1 in cancer progression has been documented in many reports. Evidence indicated that HAS1 promoted tumor proliferation and metastasis by regulating the expression of cyclin DI, E-cadherin, $\mathrm{N}$-cadherin and $\beta$-catenin in lung adenocareinoma (39). Qthers demonstrated that HAS1 regulated cell apoptosis and cell cycle arrest by modulating hyaluronic acid (HA) synthesis and HA receptor levels in bladder cancer (40). In our study, siRNA-mediated knockdown of HAS1 inhibited cell proliferation and induced cell apoptosis in KYSE70 and EC109 cells. Simultaneously, decreased expression of cell proliferation markers (Ki67 and PCNA) and increased level of cell apoptosis markers (caspase-3 and caspase-9) in EC109 cells transfected with HAS1-siRNA further identified that the inhibition of HAS1 reduced cell viabiity in ESCC cells.

Accumulated studies have suggested that HAS1 is involved in the metastasis of cancers. For example, HAS1 was found overexpressed in human primary oesophageal adenocarcinoma and upregulated HAS1 inhibited cell migration and invasion in vitro (41). HAS1 has also been demonstrated to promote cell proliferation and metastasis of osteosarcoma via regulating the activity of the $\mathrm{Wnt} / \beta$-catenin pathway (42). In our study, increased number of invasive cells and declined wound closure rate were induced by HAS1-siRNA. Besides, the expression of migration marker proteins MMP-9 and VEGF was largely suppressed in HAS1-siRNA group. The results above suggest that the inhibition of HAS1 reduces cell mobility in ESCC cells.
The role of miR-214 has been verified in numerous physiological and pathological processes, and recently, miR-214 is regarded as a regulator in various cancers. For example, miR-214 acted as a tumor suppressor by inhibiting proliferation, migration and invasion of cervical cancer cells via targeting ADP ribosylation factor like 2 (ARL2) (43). Others reported that miR-214 mediated the inhibiting effect of FOXD3 on proliferation, invasion and metastasis by targeting MED19 in colon cancer (44). Moreover, miR-214 acted as a target of LncR-LINC0086 and overexpressed miR-214 reversing the suppressive effects of LINC0086 on nasopharyngeal carcinoma (NPC) growth in vitro and in vivo (45). Generally, miRNA is regulated by the upstream transcription factors. However, the interaction between LncRNA and miR-214 in ESCC has not been revealed yet. In our study, three binding sites between between HAS1 and miR-214 were predicted through bioinformaties analysis. Contrary to the expression of HAS1 in ESCC, the level of miR-214 was downregulated in ESCC tissues and cell lines. Moreover the expression of miR-214 was suppressed by LncRNA-HAS1 and was elevated by HAS1-siRNA. The result of luciferase reporter assay further showed that luciferase activity was strongly reduced by the combination of miR-214 mimic and LncR-HAS1 WT. Results above verified that miR-214 is a target of HAS1 in ESCC cells. Increasing evidence has revealed that SOX4 is a functional target involved in tumor progression. $\mathrm{Li}$, et al found that the of miR-338-3p suppressed metastasis of lung cancer cells by binding with the 3'-UTR of Sox4 (46). In another study, propofol was verified to inhibit cell migration and invasion by downregulation of SOX4 in ESCC cell line EC9706 (47). Therefore, we explored potential SOX4-related mechanism in the progression of ESCC. In our study, complementary site of miR-214 in 3'-UTR of SOX4 was first predicted through bioinformatics analysis. Luciferase reporter assays further exhibited the targeting relationship between SOX-4 and miR-214. Relative expression of SOX4 was found downregulated by HAS1-siRNA and elevated by miR-214 inhibitor. Then, elevated expression level of SOX4 was suppressed by adding HAS1-siRNA into KYSE70 and EC107 cells pre-treated with miR-214 inhibitor. Besides, miR-214 inhibitor reversed the role of HAS1-siRNA on inhibiting cell viability and motility. Moreover, the correlations of HAS1, miR-214 and SOX4 in 35 paired cases of ESCC tissues were detected. The results showed a positive relationship between the expression level of HAS1 and SOX4, and a negative relationship between HAS1 and miR-214, miR-214 and SOX4. The results above validate that HAS1 suppresses miR-214 expression and consequently upregulates its target gene SOX4 in ESCC.

Having established that HAS1 inhibited cell viability and mobility in vitro, we further explored the effect of HAS1 in vivo. In a previous investigation, HAS1 was overexpressed in hepatocellular carcinoma (HCC) tissues and cell lines and the expression of HAS1 was closely related to tumor growth and tumor differentiation (48). In contrast, low expression of HAS1 was associated with tumor size in human gastric cancer (49). Additionally, HAS1 was upregulated in bladder cancer and high level HAS1 predicted bladder cancer metastasis (50). In support of previous concepts, HAS1-siRNA was identified to suppress ESCC tissue growth and the expression of migration marker VEGF in vivo. Furthermore, the expres- 
sion of miR-214 was upregulated and the expression of SOX-4 was downregulated by HAS1 in vivo. These results indicated a HAS1/miR-214/SOX-4 axis in regulating ESCC growth and metastasis in vivo.

In conclusion, HAS1/miR-214/SOX4 axis has an important role in the regulation of ESCC progression. HAS1 was overexpressed in ESCC tissues and cell lines. Knockdown of HAS1 inhibited cell viability and motility by targeting miR-214 to upregulate the expression of SOX4. The in vivo experiment verified that HAS1-siRNA suppressed tumor growth and metastasis. The HAS1/miR-214/SOX4 pathway might offer a promising therapeutic target for ESCC treatment.

\section{Acknowledgements}

This study was supported by the Key Research Project of Henan Educational Committee (17A310035).

\section{References}

1. Pennathur A, Gibson MK, Jobe BA and Luketich JD: Oesophageal carcinoma. Lancet 381: 400-412, 2013.

2. Feng XS, Yang YT, Gao SG, Ru Y, Wang GP, Zhou B, Wang YF, Zhang PF, Li PY and Liu YX: Prevalence and age, gender and geographical area distribution of esophageal squamous cell carcinomas in North China from 1985 to 2006. Asian Pac J Cancer Prev 15: 1981-1987, 2014.

3. Liu CY, Wang BY, Lee MY, Tsai YC, Liu CC and Shih CH: The prognostic value of circumferential resection margin in esor geal squamous cell carcinoma after concurrent chemorad therapy and surgery. J Chin Med Assoc 76: 570-575, 2013.

4. Zhao Z, Wang P, Gao Y and He J: The high expression instea mutation of p53 is predictive of overall survival in patients with esophageal squamous-cell carcinoma: A meta-analysis. Cancer Med 6: 54-66, 2017.

5. Hirajima S, Komatsu S, Ichikawa D, Shiozaki A, Morimura R, Tsujiura M et al: Clinical impact of circulating with oesophageal squamous cell 1822-1829, 2013.

6. Zhang SS, Xie X, Wen J, Luo KJ, Liu QW, Yang H, Hu Y and Fu JH: TRPV6 plays a new role in predicting survival of patients with esophageal squamous eell carcinoma. Diagn Pathol 11: 14,
2016 .

7. Wapinski $\mathrm{O}$ and Chang HY: Long noncoding RNAs and human

8. Kapranov P, Cheng J, Dike S, Nix DA, Duttagupta R, Willingham AT, Stadler PE, HertelJ, Hackermüller J, Hofacker IL, et al: RNA maps reveal new RNA classes and a possible function for pervasive transcription. Science 316: 1484-1488, 2007.

9. Hauptman $\mathrm{N}$ and Glavac D: Long non-coding RNA in cancer. Int J Mol Sci 14: 4655-4669, 2013.

10. Li J, Xuan Z and Liu C: Long non-coding RNAs and complex human diseases. Int J Mol Sci 14: 18790-18808, 2013.

11. Chambers JC, Zhang W, Sehmi J, Li X, Wass MN, Van der Harst P, Holm H, Sanna S, Kavousi M, Baumeister SE, et al; Alcohol Genome-wide Association (AlcGen) Consortium; Diabetes Genetics Replication and Meta-analyses (DIAGRAM+) Study; Genetic Investigation of Anthropometric Traits (GIANT) Consortium; Global Lipids Genetics Consortium; Genetics of Liver Disease (GOLD) Consortium; International Consortium for Blood Pressure (ICBP-GWAS); Meta-analyses of Glucose and Insulin-Related Traits Consortium (MAGIC): Genome-wide association study identifies loci influencing concentrations of liver enzymes in plasma. Nat Genet 43: 1131-1138, 2011.

12. Tammi RH, Passi AG, Rilla K, Karousou E, Vigetti D, Makkonen K and Tammi MI: Transcriptional and post-translational regulation of hyaluronan synthesis. FEBS J 278: 1419-1428, 2011.

13. Siiskonen H, Oikari S, Pasonen-Seppänen S and Rilla K: Hyaluronan synthase 1: A mysterious enzyme with unexpected functions. Front Immunol 6: 43, 2015.
14. Ma YF, Liang T, Li CR, Li YJ, Jin S and Liu Y: Long non-coding RNA HNF1A-AS1 up-regulation in non-small cell lung cancer correlates to poor survival. Eur Rev Med Pharmacol Sci 20: 4858-4863, 2016

15. Calin GA and Croce CM: MicroRNA signatures in human cancers. Nat Rev Cancer 6: 857-866, 2006.

16. Ha M and Kim VN: Regulation of microRNA biogenesis. Nat Rev Mol Cell Biol 15: 509-524, 2014.

17. Fan Z, Cui H, Xu X, Lin Z, Zhang X, Kang L, Han B, Meng J, Yan Z, Yan X, et al: MiR-125a suppresses tumor growth, invasion and metastasis in cervical cancer by targeting STAT3. Oncotarget 6: 25266-25280, 2015.

18. Ma L, Ma S, Zhao G, Yang L, Zhang P, Yi Q and Cheng S: miR-708/LSD1 axis regulates the proliferation and invasion of breast cancer cells. Cancer Med 5: 684-692, 2016.

19. Penna E, Orso F and Taverna D: miR-214 as a key hub that controls cancer networks: Small player, multiple functions. J Invest Dermatol 135: 960-969, 2015.

20. Bowles J, Schepers G and Koopman P: Phylogeny of the SOX family of developmental transcription factors based on sequence and structural indicators. Dev Biol 227: 239-255, 2000.

21. Huang YW, Liu JC, Deatherage DE, Luo J, Mutch DG, Goodfellow PJ, Miller DS and Huang TH: Epigenetic repression of microRNA-129-2 leads to overexpression of SOX4 oncogene in endometrial cancer. Cancer Res 69: 9038-9046, 2009.

22. Wang B, Li Y, Tan F and Xiao Z: Increased expression of SOX4 is associated with colorectal cancer progression. Tumour Biol 37: 9131-9137, 2016.

23. Zhang J, Jiang H, Shao J, Mao R, Luu J, Ma Y, Fang X, Zhao N, Zheng Sand Lin B: SOX 4 inhibits GBM cell growth and induces G0/G1 cell cycle arrest through Akt-p53 axis. BMC Neurol 14: $07,2014$. Tao Y, Chai D, Ma L, Zhang T, Feng Z, Cheng Z, Wu S, Qin Y and Lai M: Identification of distinct gene expression profiles etween esophageal squamous cell carcinoma and adjacent normal epithelial tissues. Tohoku J Exp Med 226: 301-311, 2012. 25. Liu J, Ma L, Li C, Zhang Z, Yang G and Zhang W: Tumortargeting TRAIL expression mediated by miRNA response elements suppressed growth of uveal melanoma cells. Mol Oncol 1043-1055, 2013.

6. Xiao H, Tang K, Liu P, Chen K, Hu J, Zeng J, Xiao W, Yu G, Yao W, Zhou H, et al: LncRNA MALAT1 functions as a competing endogenous RNA to regulate ZEB2 expression by sponging miR-200s in clear cell kidney carcinoma. Oncotarget 6: 38005-38015, 2015.

27. Li H, Yu B, Li J, Su L, Yan M, Zhu Z and Liu B: Overexpression of lncRNA H19 enhances carcinogenesis and metastasis of gastric cancer. Oncotarget 5: 2318-2329, 2014.

28. Lu Q, Xu L, Li C, Yuan Y, Huang S and Chen H: miR-214 inhibits invasion and migration via downregulating GALNT7 in esophageal squamous cell cancer. Tumour Biol 37: 14605-14614, 2016.

29. Li W, Jiang G, Zhou J, Wang H, Gong Z, Zhang Z, Min K, Zhu H and Tan Y: Down-regulation of miR-140 induces EMT and promotes invasion by targeting Slug in esophageal cancer. Cell Physiol Biochem 34: 1466-1476, 2014.

30. Xu XC: Risk factors and gene expression in esophageal cancer. Methods Mol Biol 471: 335-360, 2009.

31. Kosugi S, Nishimaki T, Kanda T, Nakagawa S, Ohashi M and Hatakeyama K: Clinical significance of serum carcinoembryonic antigen, carbohydrate antigen 19-9, and squamous cell carcinoma antigen levels in esophageal cancer patients. World J Surg 28: 680-685, 2004.

32. Lee J, Jung JH, Chae YS, Park HY, Kim WW, Lee SJ, Jeong JH and Kang SH: Long noncoding RNA snaR regulates proliferation, migration and invasion of triple-negative breast cancer cells. Anticancer Res 36: 6289-6295, 2016.

33. Ponting CP, Oliver PL and Reik W: Evolution and functions of long noncoding RNAs. Cell 136: 629-641, 2009.

34. Golshani R, Hautmann SH, Estrella V, Cohen BL, Kyle CC, Manoharan M, Jorda M, Soloway MS and Lokeshwar VB: HAS1 expression in bladder cancer and its relation to urinary HA test. Int J Cancer 120: 1712-1720, 2007.

35. Yamada Y, Itano N, Narimatsu H, Kudo T, Morozumi K, Hirohashi S, Ochiai A, Ueda M and Kimata K: Elevated transcript level of hyaluronan synthasel gene correlates with poor prognosis of human colon cancer. Clin Exp Metastasis 21: 57-63, 2004.

36. Yabushita H, Noguchi M, Kishida T, Fusano K, Noguchi Y, Itano N, Kimata K and Noguchi M: Hyaluronan synthase expression in ovarian cancer. Oncol Rep 12: 739-743, 2004. 
37. Nykopp TK, Rilla K, Tammi MI, Tammi RH, Sironen R, Hämäläinen K, Kosma VM, Heinonen S and Anttila M: Hyaluronan synthases (HAS1-3) and hyaluronidases (HYAL1-2) in the accumulation of hyaluronan in endometrioid endometrial carcinoma. BMC Cancer 10: 512, 2010.

38. Poukka M, Bykachev A, Siiskonen H, Tyynelä-Korhonen K, Auvinen P, Pasonen-Seppänen S and Sironen R: Decreased expression of hyaluronan synthase 1 and 2 associates with poor prognosis in cutaneous melanoma. BMC Cancer 16: 313, 2016.

39. Wu Y, Liu H, Shi X, Yao Y, Yang W and Song Y: The long non-coding RNA HNF1A-AS1 regulates proliferation and metastasis in lung adenocarcinoma. Oncotarget 6: 9160-9172, 2015.

40. Golshani R, Lopez L, Estrella V, Kramer M, Iida N and Lokeshwar VB: Hyaluronic acid synthase-1 expression regulates bladder cancer growth, invasion, and angiogenesis through CD44. Cancer Res 68: 483-491, 2008.

41. Yang X, Song JH, Cheng Y, Wu W, Bhagat T, Yu Y, Abraham JM, Ibrahim S, Ravich W, Roland BC, et al: Long non-coding RNA HNF1A-AS1 regulates proliferation and migration in oesophageal adenocarcinoma cells. Gut 63: 881-890, 2014.

42. Zhao H, Hou W, Tao J, Zhao Y, Wan G, Ma C and Xu H: Upregulation of 1ncRNA HNF1A-AS1 promotes cell proliferation and metastasis in osteosarcoma through activation of the Wnt/ $\beta$-catenin signaling pathway. Am J Transl Res 8: 3503-3512, 2016.

43. Peng R, Men J, Ma R, Wang Q, Wang Y, Sun Y, Ren J: miR-214 down-regulates ARL2 and suppresses growth and invasion of cervical cancer cells. Biochem Biophys Res Commun 484: 623-630, 2017
44. He GY, Hu JL, Zhou L, Zhu XH, Xin SN, Zhang D, Lu GF, Liao WT, Ding YQ and Liang L: The FOXD3/miR-214/MED19 axis suppresses tumour growth and metastasis in human colorectal cancer. Br J Cancer 115: 1367-1378, 2016.

45. Guo J, Ma J, Zhao G, Li G, Fu Y and Luo Y: Long non-coding RNA LINC0086 functions as a tumor suppressor in nasopharyngeal carcinoma by targeting miR-214. Oncol Res: Feb 13, 2017 (Epub ahead of print). doi: 10.3727/096504017X148651266700 75.2017.

46. Li Y,Chen P,Zu L, Liu B, Wang M and Zhou Q: MicroRNA-338-3p suppresses metastasis of lung cancer cells by targeting the EMT regulator Sox4. Am J Cancer Res 6: 127-140, 2016.

47. Zhou CL, Li JJ and Ji P: Propofol suppresses esophageal squamous cell carcinoma cell migration and invasion by downregulation of Sex-Determining Region Y-box 4 (SOX4). Med Sci Monit 23: 419-427, 2017.

48. Liu Z, Wei X, Zhang A, Li C, Bai J and Dong J: Long non-coding RNA HNF1A-AS1 functioned as an oncogene and autophagy promoter in hepatocellular carcinoma through sponging hsa-miR-30b-5p. Biochem Biophys Res Commun 473: 1268-1275, 2016.

49. Dang Y, Lan F, Ouyang X, Wang K, Lin Y, Yu Y, Wang L, Wang $Y$ and Huang Q: Expression and clinical significance of long non-coding RNA HNF1A-AS1 in human gastric cancer. World J Surg Oncol 13: 302, 2015.

50. Kramer MW, Escudero DO, Lokeshwar SD, Golshani R, Ekwenna OO, Acosta K, Merseburger AS, Soloway M and Lokeshwar YB: Association of hyaluronic acid family members (HAS1, HAS2, and HYAL-1) with bladder cancer diagnosis and prognosis. Cancer 117: 1197-1209, 2011.

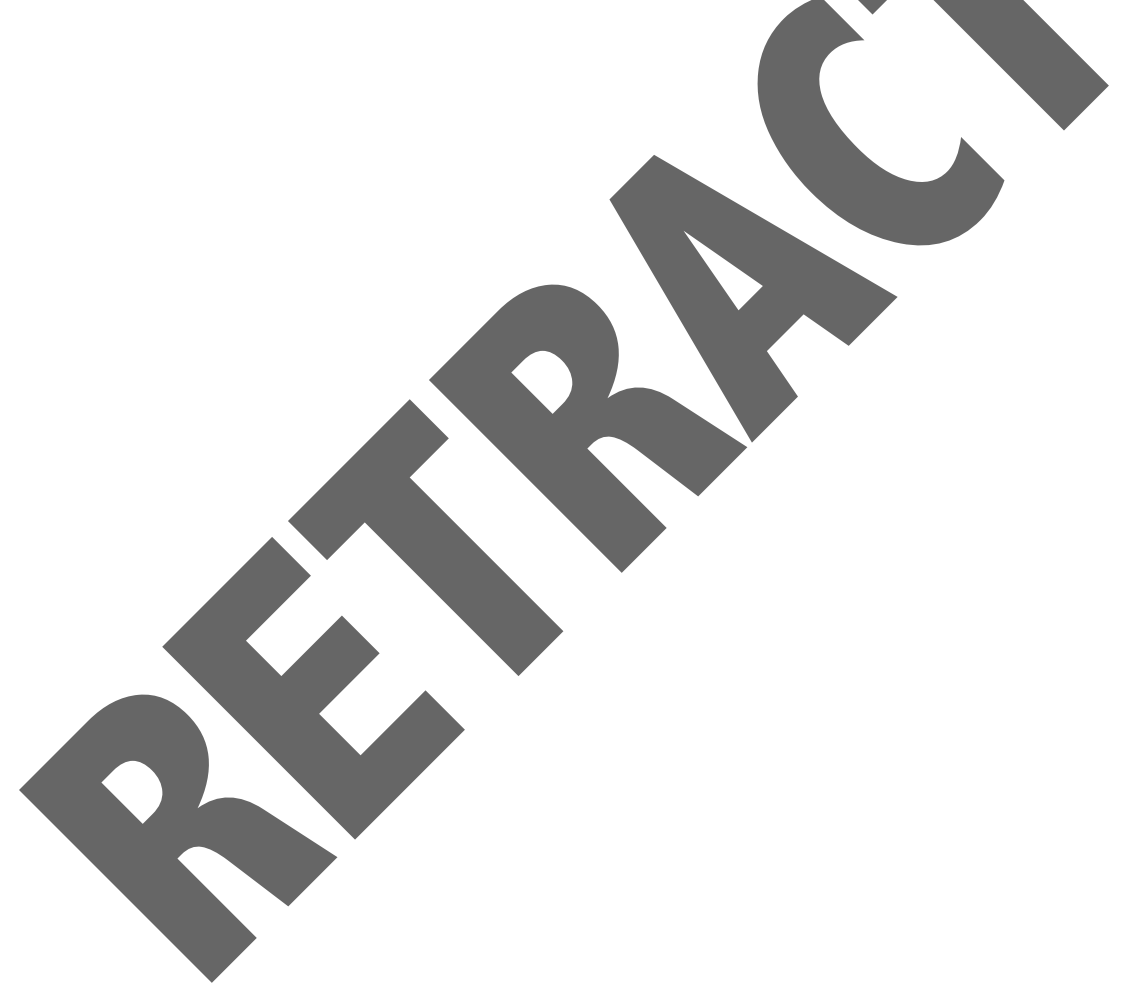

